\begin{tabular}{|l|c|}
\hline Proceeding of the $9^{\text {th }}$ ICEE Conference 3-5 April 2018 & CEA \\
Military Technical College \\
Kobry El-Kobbah, \\
Cairo, Egypt
\end{tabular}

\title{
CEA-4
}

\section{Combustion characteristics of extruded nitramine double-base propellants}

\author{
Ashraf M. A. Elghafour ${ }^{\text {a }}$, Mostafa A. Radwan ${ }^{\text {a }}$, Hosam E. Mostafa ${ }^{\text {a }}$, Ahmed Fahd ${ }^{\text {a }}$, \\ Sherif Elbasuney ${ }^{a *}$
}

\begin{abstract}
The burning rate-pressure relation of solid propellant is an exponential relation; this is means catastrophic combustion process in case of sudden increase in operating pressure. This study reports on novel approach to minimize the dependence of burning rate on the operating pressure using highly energetic nitramines (RDX). Nitramine-based double base propellants with RDX content up to $20 \mathrm{wt} \%$ were manufactured by solventless extrusion technology. The impact of RDX content on burning rate, specific impulse, exhaust velocity, and thrust were evaluated using small-scale ballistic evaluation rocket motor. Specific impulse (Is) was enhanced by $20 \%$. The action burning time (tb) was increased by $14 \%$. The total thrust impulse (IFT) was significantly improved by $22 \%$. One of the main outcomes of this study is that burning rate pressure exponent (n) which was decreased significantly from 0.35 to 0.05 . This novel ballistic performance means minimal change in burning rate with pressure variation. These novel findings confirmed that RDX has a dual function as energetic filler and as a platonizing agent. This is the first time ever RDX has been reported to act as a platonizing agent. It can be concluded that many advantages have been achieved with one shot.
\end{abstract}

\section{Keywords:}

Combustion, Double-base propellants, Burning rate, Ballistic performance, Platonizing, Nitramines

School of chemical Engineering, Military Technical College, Cairo, Egypt s.elbasuney@mtc.edu.eg, sherif_basuney2000@yahoo.com, +201112630789 


\section{Military Technical College \\ Kobry El-Kobbah, Cairo, Egypt}

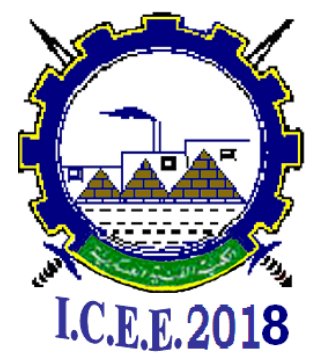

9 $\frac{\text { th }}{\text { International Conference }}$ on

Chemical \& Environmental Engineering

3-5 April 2018

\section{Introduction}

Double base (DB) propellants consist mainly of high molecular weight nitrocellulose (NC) plasticized or gelatinized with liquid nitrate esters mainly nitroglycerine (NG); they are best known as smokeless propellants [1]. In fact, NC and NG bring together carbon, hydrogen, and oxygen necessary for the exothermic combustion reaction[2]. The oxidizing and reducing elements which are involved in the release of energy through combustion are combined in the same molecule; they are known as homogenous propellants [3]. Other minor additives are also included in DB propellants to improve their chemical, mechanical, and ballistic properties [4-7]. DB propellants are candidate for tactical missile propulsion as they can offer many advantages including:

* Little or no solid particles in the gas jet.

* Good mechanical properties.

* High chemical and thermal stability.

* Low sensitivity to propellant temperature.

* Good aging capabilities, particularly under humid conditions.

However the burning rate of DB propellant is highly dependent on the operating pressure. The burning rate-pressure is an exponential relation as represented by equation 1 .

$$
\mathrm{r}=\mathrm{a} \mathrm{P}^{\mathrm{n}}
$$

Where: a is the burning rate constant, $\mathrm{P}$ is the operating pressure, and $\mathrm{n}$ is the pressure exponent[8]. Equation 1 confirms the fact that any minimal change in operating pressure will result in a dramatic increase in burning rate. This means a catastrophic combustion process which might lead to rocket motor explosion. NC is the main energetic constituent of DB propellants [6]. One of the main features of NC combustion characteristics is that it combusts with the generation of large quantity of $\mathrm{CHO}$ free radical[9]. That is why $\mathrm{NC}$ is one of the key factors to ensure burning rate modification in smokeless propellants. The inclusion of small quantities of various inorganic lead salts in DB propellants can result in so called plateau or mesa burning over specified region of operating pressure (Figure 1).

Catalyzed DB propellants can demonstrate an increase in burning rate with burning rate at low pressure values. This behavior is followed by plateau burning region, where the burning rate remains almost independent of pressure variation. Platonized region is characterized with $\mathrm{n}$ value ranging from 0:0.3. The post-plateau region is similar to that of un-catalyzed DB propellants [10]. It is clearly apparent that the magnitude of $\mathrm{n}$ is one of the most important factors for controlled combustion behavior and the suitability of DB propellants for propulsion systems [11]. 


\section{Military Technical College \\ Kobry El-Kobbah, Cairo, Egypt}

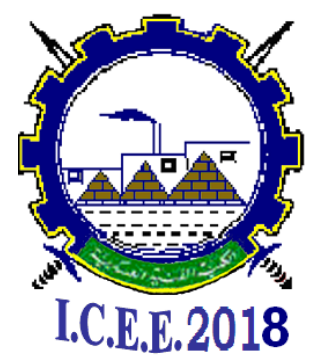

$9^{\text {th }}$ International Conference on

Chemical \& Environmental Engineering

3-5 April 2018

The combustion wave can have a significant impact on DB propellant patronization. Energetic constituents that can self-decompose with the release massive free radicals as well as inert gases have the potential to minimize the burning rate dependence on operating pressure [2]. It is widely accepted that the combustion wave of DB propellants consists of five distinctive zones; each zone is characterized with specific chemical reaction as demonstrated in Figure 2.

\section{I) Heat conduction zone.}

No chemical reactions associated with this zone. The thermal effect provided by heat conduction from the burning surface causes temperature increase from the initial temperature to the onset decomposition temperature Tu.

\section{II) Solid phase reaction zone.}

The solid phase reaction zone is a very thin layer with temperature equal to the burning surface temperature Ts. The overall reactions in this zone are exothermic degradation.

\section{III) Fizz zone.}

This zone is just above the burning surface where a series of degradation reactions occur very rapidly in the early stages of the gas phase reaction zone.

\section{IV) Dark zone.}

This zone is characterized by very slowly oxidation reactions between the products.

\section{V) Flame zone.}

This zone is characterized by high flame temperature where final combustion products are formed, and the combustion products reach the thermal equilibrium state.

Energetic heterocyclic nitramine (RDX) can be ideal energetic filler for DB propellants. RDX can offer potential characteristics including [13]:

- High thermal stability with decomposition temperature $2130 \mathrm{C}$

- High enthalpy of formation $+318 \mathrm{KJ} / \mathrm{Kg}$

- High heat of combustion $5.647 \mathrm{KJ} / \mathrm{Kg}$

- High volume of gaseous products $903 \mathrm{~L} / \mathrm{Kg}$

All these features can inherit RDX a vital role for the development of DB propellants. Therefore RDX can significantly enhance the combustion characteristics in terms of specific impulse (thrust per unit weight of effective propellant), as well as burning rate. RDX can act as a blowing agent generating large amount of inert gasses pushing the luminous flame from the burning surface. Therefore it can offer superior platonization 
Military Technical College Kobry El-Kobbah, Cairo, Egypt

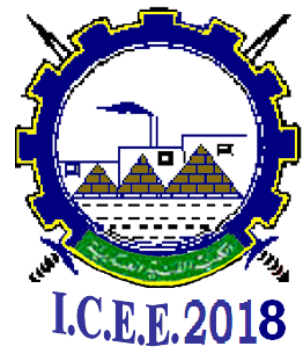

$9^{\text {th }}$ International Conference on

Chemical \& Environmental Engineering

3-5 April 2018

characteristics.

In this study, MDB formulations based on RDX as energetic filler were developed by solventless extrusion technique. The impact of RDX content on combustion characteristics particularly burning rate, specific impulse, exhaust velocity, and thrust were evaluated using small-scale ballistic evaluation test motor; which has been established as the most representative testing mean [14]. RDX demonstrated a dual effect as energetic filler and as a platonizing agent. It enhanced the specific impulse and action burning time increased by $20 \%$ and $14 \%$ respectively. Hence, the total thrust impulse was significantly improved by $22 \%$. It offered novel platonization of burning rate with $\mathrm{n}$ value of 0.05 . This is the first time ever to report on DB propellant platonization using RDX.

\section{Manufacture of DB propellants}

The manufacture technology should emphasize mixing of different ingredients to molecular level, good homogenization, high density, as well as dimensional stability of final product [6]. Solventless extrusion technique can fulfill these requirements. The production technology includes different main stages including [15]:

* Mixing of different ingredients to insure homogenization.

* Rolling phases to remove water and insure gelatinization by dual effect of pressure and heat.

* Screw extrusion with variable feeding system under controlled temperature and pressure to obtain the final shape.

* Figure 3 is a schematic of solventless extrusion technology.

DB propellants with RDX content up to 20 wt $\%$ were developed by solventless extrusion technique. Ultrafine RDX with average particle size of $12 \mu \mathrm{m}$ was employed. Figure 4 demonstrated the average particle size using Transmission electron microscope (TEM).

The chemical composition of developed DB propellant formulations is represented in table 1 .

\section{Combustion characteristics of DB propellants}

Small-scale ballistic evaluation test motor is widely accepted as an effective method to measure the real combustion characteristics during static firing [14]. One-inch test motor (33 $\mathrm{mm} \mathrm{ID}$ and $225 \mathrm{~mm}$ length) was employed[16] (Figure 5).

The pressure $(\mathrm{P})$ inside the combustion chamber was recorded with time ( $\mathrm{t}$ ) during DB 


\author{
Military Technical College \\ Kobry El-Kobbah, \\ Cairo, Egypt
}

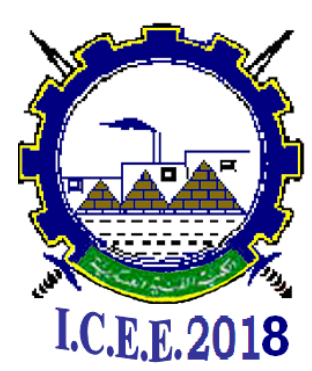

$9^{\text {th }}$ International Conference on

Chemical \& Environmental Engineering

3-5 April 2018

propellant combustion. Based on pressure-time curve, the average operating pressure, burning time, burning rate, and characteristic exhaust velocity were evaluated [17]. In the meantime the thrust was recorded with time during combustion process. All developed DB propellant formulations demonstrated ideal stable burning over the combustion process. This confirms the fact that modified DB propellants free from defects (cracks, air bubbles) with good homogeneity have been developed. The pressure-time curves of developed modified DB propellants are represented in Figure 6 [18].

Even though modified DB propellants demonstrated combustion behavior similar to reference formulation in terms of operating pressure; they exhibited extended burning/action time. This combustion behavior means enhanced total impulse. There was an increase in specific impulse (s), characteristic velocity $(\mathrm{m} / \mathrm{s})$, thrust $(\mathrm{N})$, total impulse (N S) and action burning time (S) with RDX content (Table 2).

$\mathrm{RDX}$ as an energetic explosive material with slightly negative oxygen balance, and high combustion temperature can offer high amount of low molecular weight combustion gaseous products. This action could withstand the enhanced combustion characteristics. There was a decrease in burning rate with RDX content. All these features inspired us to deeply investigate the impact of RDX content on burning rate-pressure relation as it can act as a novel platonizing agent [19].

\section{Platonization of DB propellants}

RDX can act as an energetic blowing agent, releasing massive amount of gasses, pushing the flame zone from the burning surface. The burning rate for each developed modified DB formulation was measured at different operating pressure. Five static firing tests have been conducted for each developed formulation. The operating pressure was changed by changing the throat diameter of small-scale rocket motor. The burning rate-pressure relation for each developed formulation was plotted (Figure 7).

Figure 7 shows the burning rate (r) versus pressure (P) of the plateau RDX-MDB propellants with different content of RDX. The pressure index (n) of each developed formulation is represented. There was a decrease in $\mathrm{n}$ value with the increase in RDX content. Consequently RDX offered insensitive combustion pressure to operating pressure flocculation. RDX could alter the combustion mechanism by cooling down the burning surface during melting and alter the chemical reactions associated with each combustion zone described in Figure 2. 


\section{Military Technical College \\ Kobry El-Kobbah, Cairo, Egypt}

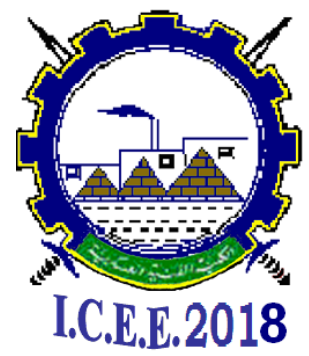

$9^{\text {th }}$ International Conference on

Chemical \& Environmental Engineering

3-5 April 2018

\section{Platonization mechanism with RDX}

Oxygen content in RDX is not enough for complete oxidation of fuel elements $(\mathrm{C}, \mathrm{H})$. Therefore RDX can produce large quantity of inert gasses as N2 as well as carbon black. Active carbon black can react with the combustion product such as $\mathrm{PbO}$ as follows:

$$
\begin{aligned}
& P b O_{(s)}+C_{(s)}=P b_{(s)}+C O_{(g)} \Delta H=108.68 \mathrm{~kJ} / \mathrm{mol} \\
& P b O_{(s)}+C O_{(g)}=P b_{(s)}+C O_{2}(g) \Delta H=-63.79 \mathrm{~kJ} / \mathrm{mol}
\end{aligned}
$$

Lead metal product from the above reactions plays a key role in the plateau effect. Under the static ambient condition, lead metal is used as catalyst in the oxidation-reduction reactions. Combustion process with high content of active carbon black will increase the generated lead metal. This action could strengthen the platonization effect of DB propellants[20]. Substantial amount of N2 through the C-N bond breaking in the nearsurface region will be resulted during RDX decomposition [10]. The pressure of $\mathrm{N} 2$ and large fuel fragments dilute the concentrations of surface reactive species. This blowing effect tends to push the primary flame away from the surface (Figure 8) [21].

Therefore, a thin luminous flame zone stands some distance from the burning surface and a reddish flame is produced above this luminous flame zone. The luminous flame becomes stable and one-dimensional just above the burning surface when the pressure is high enough [22]. It was presumed that the different thermal decomposition process of the nitrogen heterocyclic nitramines lead to the different flame diffusing model (Fig. 9) $[22]$.

Thermal decomposition of RDX remains with the solid to liquid state reaction [23]. There are crystals transformations before the thermolysis of RDX [24]. Therefore the gas, liquid, and solid phases exist in its condensed phase reaction zone. This endothermic phase change could cool down the burning surface. Furthermore, the concave and convex burning surface can increase the surface area of gaseous products jet, thus radial diffusion becomes more important, resulting shorter flames [23].

\section{Conclusion}

RDX with high thermal stability, combustion heat of $5.647 \mathrm{~kJ} / \mathrm{g}$, and gaseous products of $903 \mathrm{~L} / \mathrm{Kg}$ could be an effective energetic filler for DB propellants. The impact of RDX content on combustion characteristics of DB propellants was evaluated using small-scale 
Military Technical College

Kobry El-Kobbah,

Cairo, Egypt

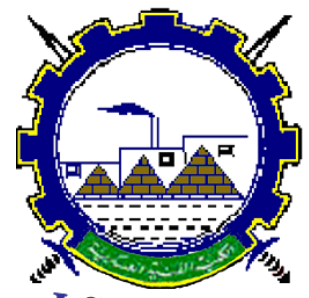

I.C.E.E.2018 $9^{\text {th }}$ International Conference

on

Chemical \& Environmental

Engineering

3-5 April 2018

ballistic evaluation test motor. RDX significantly enhanced the specific impulse by $20 \%$, $\mathrm{C}^{*}$ by $3 \%$, thrust by $7 \%$, and action burning time by $14 \%$. Finally, the total impulse was significantly improved by $22 \%$.

The novel finding is that RDX lowered the sensitivity of burning rate to operating pressure over wide range of pressure (100-140 bars). The pressure exponent $\mathrm{n}$ was decreased from 0.3 to 0.05 . This novel platonization action was ascribed to its blowing effect therefore pushing the luminous flame to some extent from the burning surface, as well as the generation of free lead metal which could strengthen the platonization effect. RDX could cool down the burning surface due to its endothermic phase transition over decomposition.

\section{Reference}

[1] Sutton, G., In Rocket Propulsion Elements, W.I. Publication, Editor. 1986: New York.

[2] Hayri Yaman, V.D., E. , Experimental Investigation of the Factors Affecting the Burning Rate of Solid Rocket Propellants. Fuel 2014. 115: p. 794-803.

[3] Sutton GP, B.O., Solid propellant rocket fundamentals. In: Rocket propulsion elements. 2011: Wiley.

[4] Sun C, X.J., Chen X, Zheng J, Zheng Y, Wang W, Strain rate and temperature dependence of the compressive behavior of a composite modified double-base propellant. Mech Mater, 2015. 89: p. 35-46.

[5] Wu X-G, Y.Q.-L., Guo X, Qi X-F, Li X-J, Wang K-Q Combustion efficiency and pyrochemical properties of micron-sized metal particles as the components of modified double-base propellant Acta Astronaut, 2011. 68 p. 1098-1112.

[6] Davenas, A., Ed., Pergamon Press, Oxford, Solid Rocket Propulsion Technology. 2012.

[7] Kakami A, T.T., Heat balance evaluation of double-base solid propellant combustion using thermography and laser heating on a burning surface. Aerosp Sci Technol 2015. 47: p. 86-91.

[8] D. Chakraboty, M.C.L., in: V. Yang, T.B. Brill, W.Z., Solid Propellant Chemistry, Combustion, and Motor Interior Ballistics, in: Progress in Astronautics and Aeronautics. AIAA, 2000. vol. 185: p. p. 33.

[9] Kubota, N., Propellants and Explosives: Thermochemical Aspects of Combustion. 2015: Wiley.

[10]F.q. Zhao, S.-w.L., J. Propul. Technol, 1992. 13 (1) p. 57-62. 
Military Technical College

Kobry El-Kobbah,

Cairo, Egypt

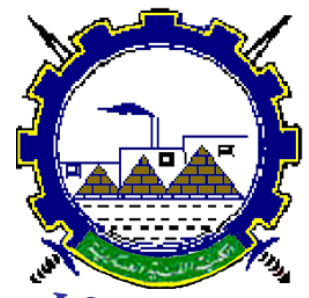

I.C.E.E.2018 $9^{\text {th }}$ International Conference

on

Chemical \& Environmental

Engineering

3-5 April 2018

[11]Doisneau, F., Eulerian Multi-fluid Models for the Simulation of Dynamics and Coalescence of Particles in Solid Propellant Combustion. J. Comput. Phys., 2013. 234: p. 230-262.

[12] Sadek, R., et al., Novel yellow colored flame compositions with superior spectral performance. Defence Technology, 2017. 13(1): p. 33-39.

[13] Meyer, J., A. Explosives. 6th ed. 2007, Homburg: Wiley-VCH, Weinheim

[14] Sutton, G.P. and O. Biblarz, Solid propellant rocket fundamentals, in Rocket Propulsion Elements. 2011, Wiley.

[15]TJ., L., The effect of processing variations on the ballistics of fast burning extruded double base propellants., in In: AIAA 14th joint propulsion conference. 1978.

[16] Sutton GP, B.O., Nozzle theory and thermodynamic relations. In: Rocket propulsion elements. 2011: Wiley.

[17]R.Fry, L.D., R. Frederick, G. Gadiot, and R. Strecker, "Evaluation of methods for solid propellant burning rate measurement," Defense technical information center ( DTIC) Document, USA, 2002.

[18] Agrawal, J.P., High Energy Materials: Propellants, Explosives and Pyrotechnics. 2010: Wiley.

[19]Gautarn, S.J., A.; Mulage, K.; Singh, S. , Study of Energetic Nitramine Extruded Double-base Propellants. Def. Sci. J., 1998. $148: 2$.

[20]Dreizin, E.L., Metal-based reactive nanomaterials. Progress in Energy and Combustion Science, 2009. 35(2): p. 141-167.

[21]Han, W.H., D.; Li, S.; Zhao, F.; Zhang, L. . . RDX/AP-CMDB Propellants Containing Fullerenes and Carbon Black Additives. Def. Sci. J, 2009,. 9: : p. 59-68.

[22] Yan Qi-Long a, L.X.-J., Wang Yinga, Zhang Wei-Hua b, Zhao Feng-Qi, Combustion mechanism of double-base propellant containing nitrogen heterocyclic nitroamines (I): The effect of heat and mass transfer to the burning characteristics. Combustion and Flame, 2009. 156 p. 633-641.

[23] Miller, M.S., J. Thermophys. Heat Transfer, 1994. 8 (4): p. 803-805.

[24]R. Shaw, F.E.W., J. Phys. Chem 1977. 81 (25): p. 2572-2576. 
Military Technical College Kobry El-Kobbah, Cairo, Egypt

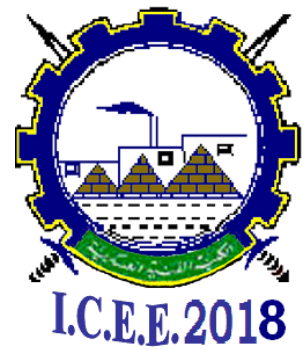

$9^{\text {th }}$ International Conference on

Chemical \& Environmental

Engineering

3-5 April 2018

Table 1: The chemical composition of the reference DB propellant and developed NDBP formulations (combine the two columns)

\begin{tabular}{lccccc}
\hline & $\begin{array}{c}\mathrm{NC} \\
(\mathrm{wt} \%)\end{array}$ & $\begin{array}{c}\mathrm{NG} \\
(\mathrm{wt} \%)\end{array}$ & $\begin{array}{c}\text { Stabilizers } \\
(\mathrm{wt} \%)\end{array}$ & $\begin{array}{c}\text { Other } \\
\text { additives } \\
(\mathrm{wt} \%)\end{array}$ & $\begin{array}{c}\text { RDX } \\
(\mathrm{wt} \%)\end{array}$ \\
\hline F0 (Reference) & 57.70 & 30.30 & 2.90 & 9.10 & 0 \\
\hline F1 (5 wt \% RDX) & 54.82 & 28.78 & 2.76 & 8.64 & 5 \\
\hline F2 (10 wt \% RDX) & 51.93 & 27.27 & 2.61 & 8.19 & 10 \\
\hline F3 (15 wt \% RDX) & 49.04 & 25.75 & 2.47 & 7.74 & 15 \\
\hline F4 (20 wt \% RDX) & 46.16 & 24.24 & 2.32 & 7.28 & 20 \\
\hline
\end{tabular}

Table 2: Ballistic properties of NDBP formulations

\begin{tabular}{cccccc}
\hline Characteristics & $\mathrm{F}_{1}$ & $\mathrm{~F}_{2}$ & $\mathrm{~F}_{3}$ & $\mathrm{~F}_{4}$ & $\mathrm{~F}_{5}$ \\
\hline $\begin{array}{c}\text { Specific Impulse (s) } \\
\begin{array}{c}\text { Characteristic Velocity } \\
(\mathrm{m} / \mathrm{s})\end{array}\end{array}$ & 151.2 & 178.3 & 189.4 & 193 & 505.7 \\
Thrust (N) & 1535 & 1538 & 1541 & 1556 \\
Total Impulse (N.s) & 549 & 361 & 390 & 401 & 1426 \\
Burning rate (mm/s) & 2.5 & 12.46 & 12.22 & 11.48 & 0.95 \\
\hline Action burning time (s) & 0.359 & 0.365 & 0.369 & 0.388 & 0.41 \\
\hline
\end{tabular}




\begin{tabular}{|l|l|}
\hline Proceeding of the $9^{\text {th }}$ ICEE Conference 3-5 April 2018 & CEA \\
\hline
\end{tabular}

Military Technical College

Kobry El-Kobbah,

Cairo, Egypt

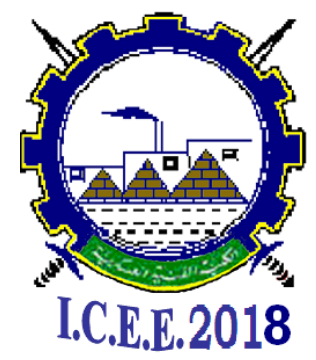

$9^{\text {th }}$ International Conference on

Chemical \& Environmental

Engineering

3-5 April 2018

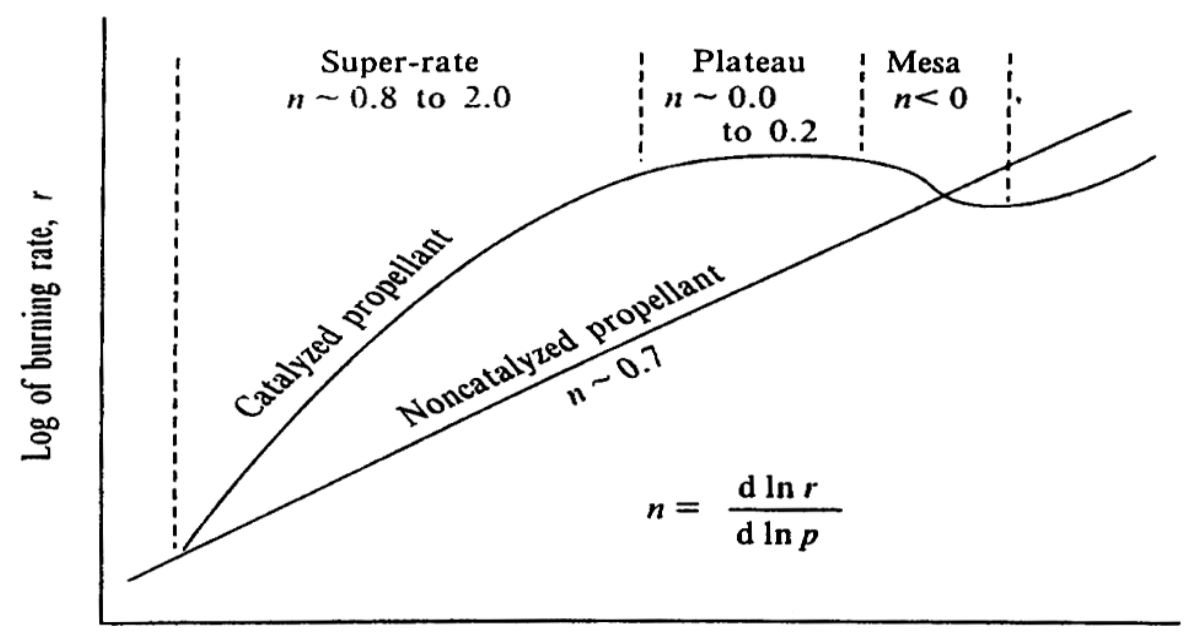

Log of pressure, $p$

Fig. 1: Burning rate -pressure relation for non-catalyzed and catalyzed DB propellants

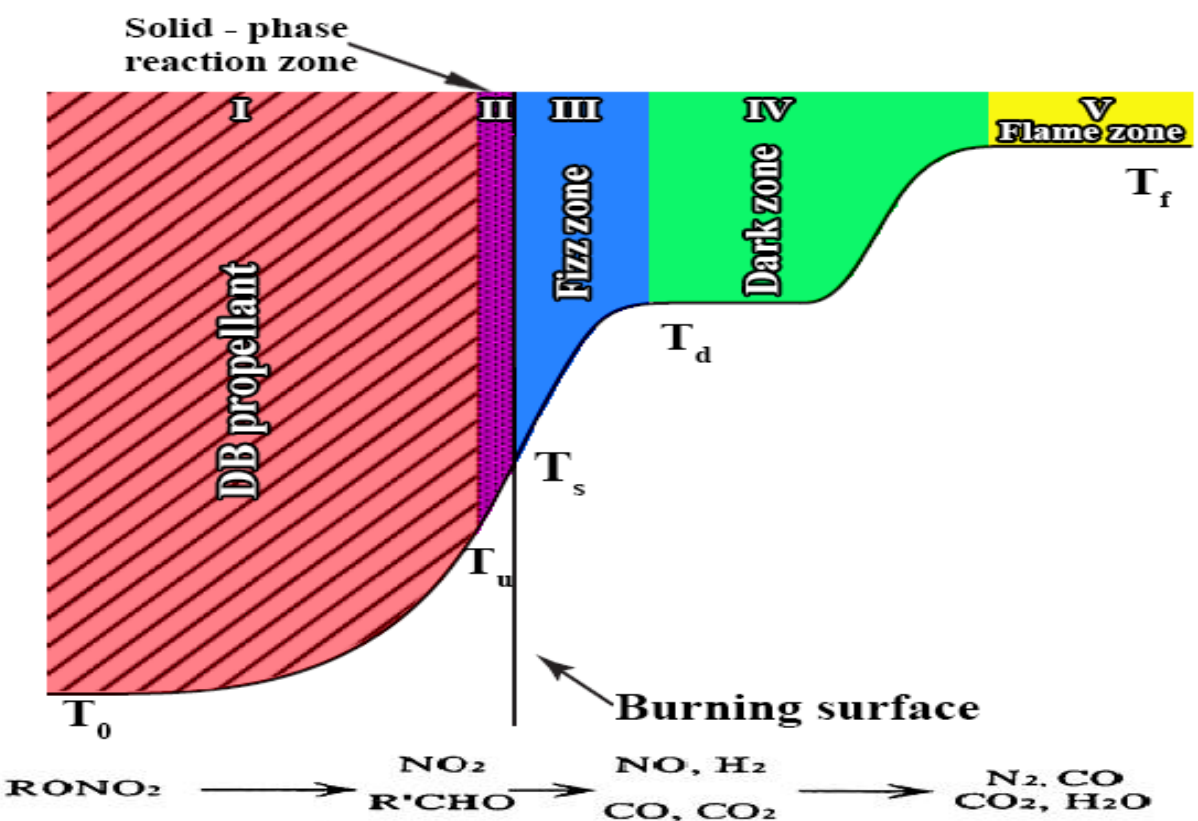

Fig. 2: Combustions zones of DB propellants with associated chemical reactions[12] 
Military Technical College

Kobry El-Kobbah,

Cairo, Egypt

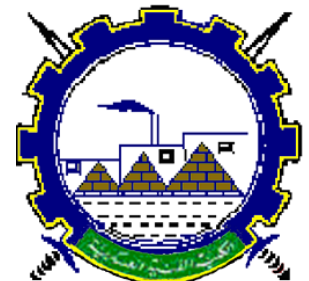

I.C.E.E.2018 $9^{\text {th }}$ International Conference on

Chemical \& Environmental

Engineering

3-5 April 2018

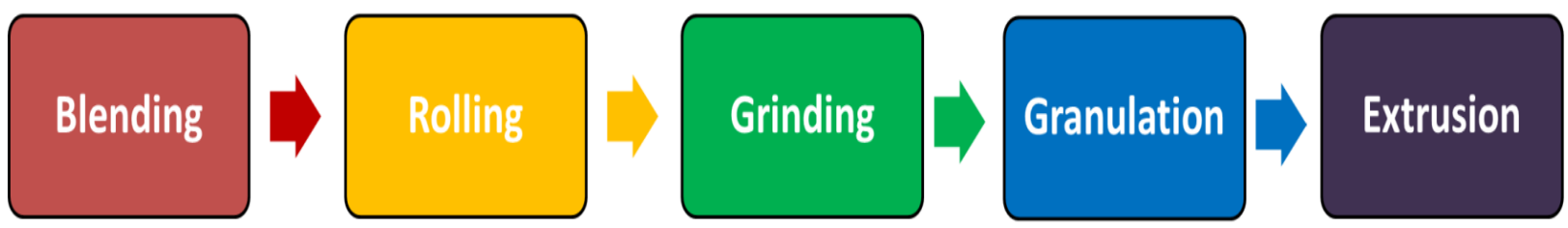

Fig. 3: Schematic for solventless extrusion process for manufacture of MDB propellant

\begin{tabular}{|r|r|r|r|r|r|r|r|}
\hline & N total & Mean & Standar Sum & Minimu & Median & Maximu \\
\hline B & 22 & 13 & 5.4072 & 286 & 5 & 12 & 27 \\
\hline
\end{tabular}

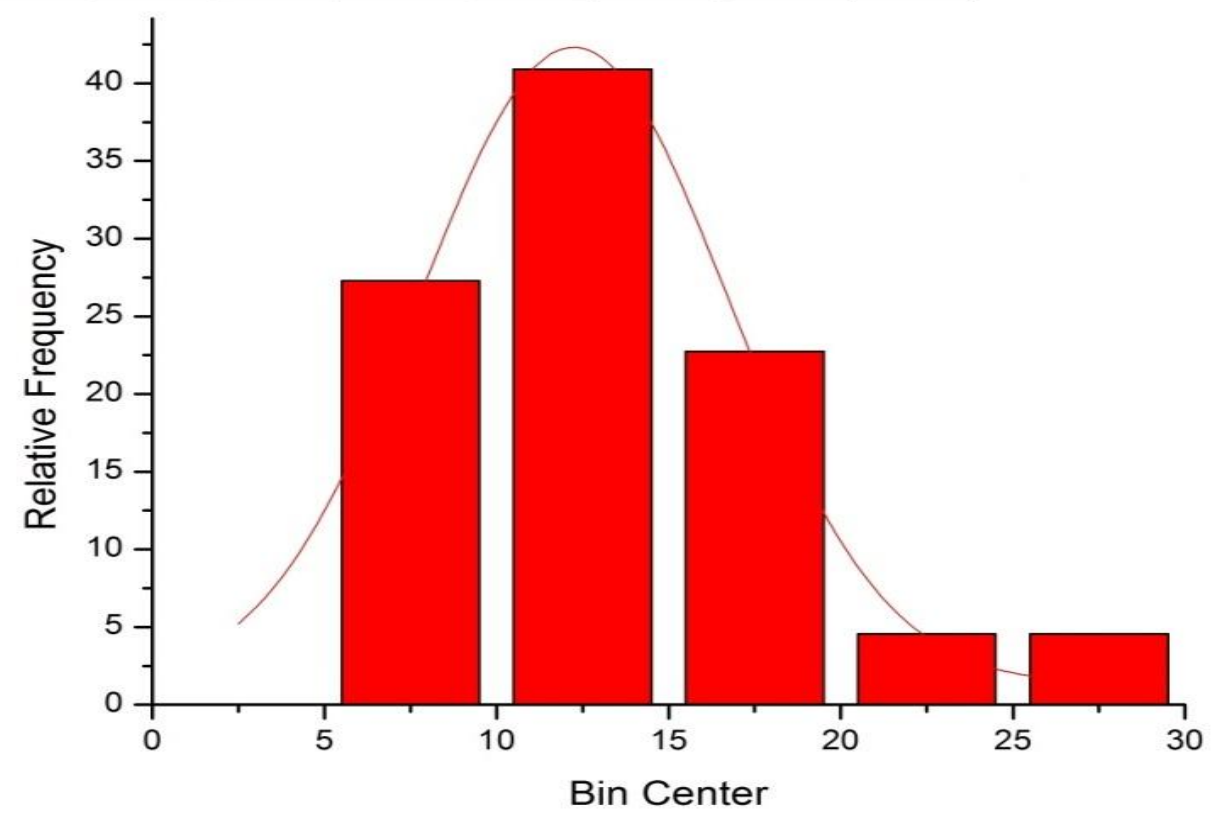

Fig. 4: RDX particle size by Transmission Electron Microscope (TEM) 
\begin{tabular}{|l|l|}
\hline Proceeding of the $9^{\text {th }}$ ICEE Conference 3-5 April 2018 & CEA \\
\hline
\end{tabular}

Military Technical College

Kobry El-Kobbah,

Cairo, Egypt

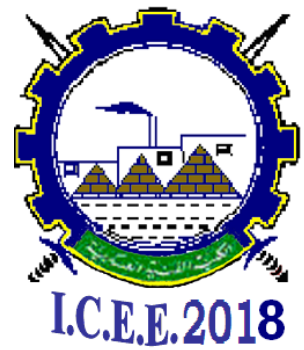

225.00

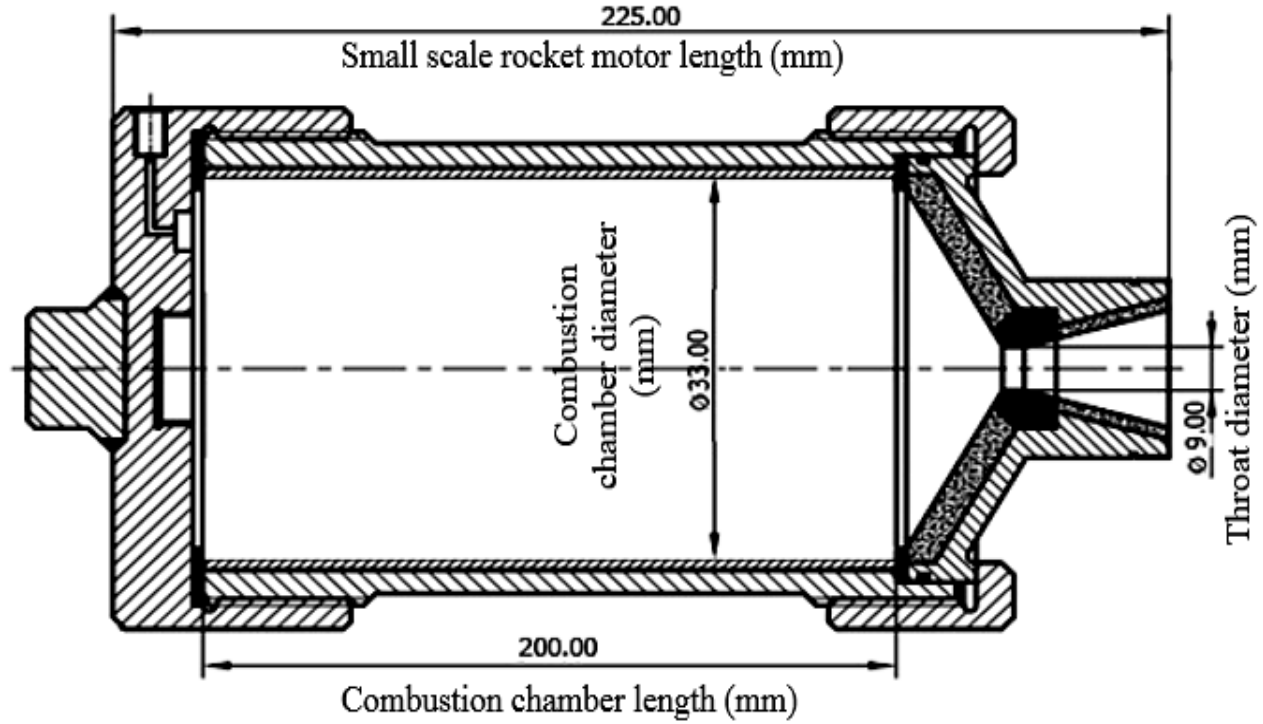

Fig. 5: Schematic for employed small scale ballistic evaluation test motor during static firing test

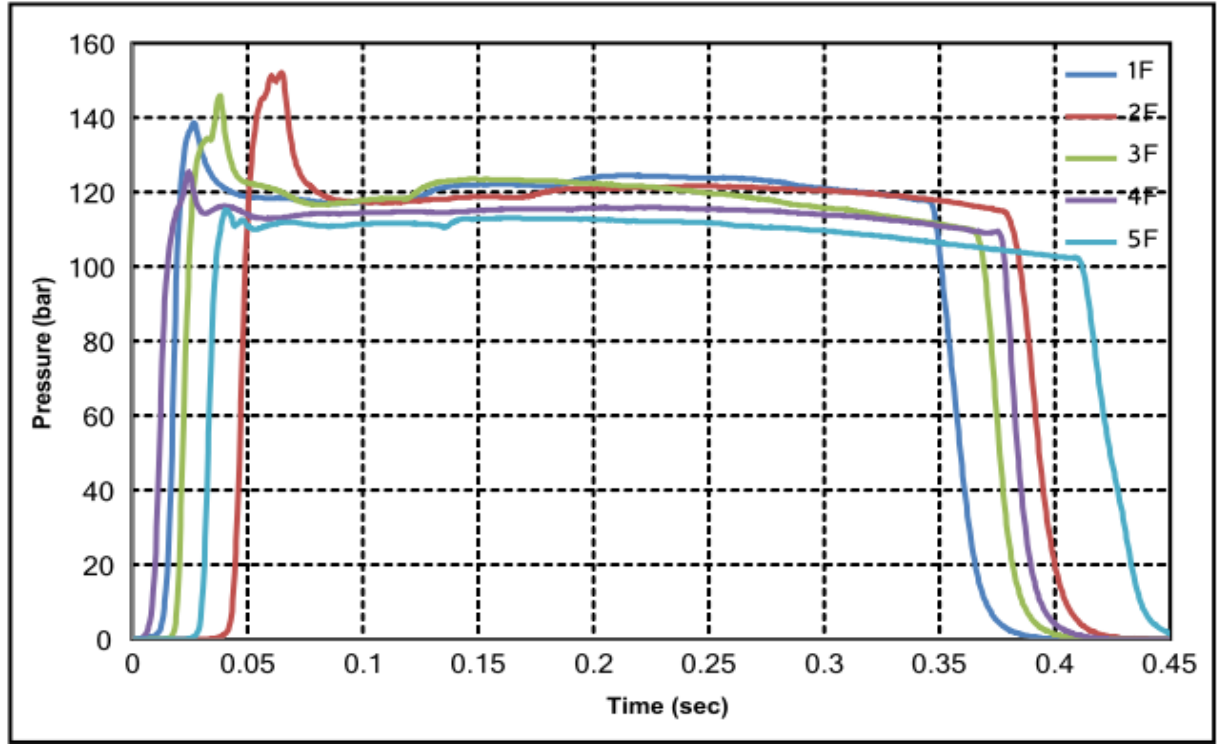

Fig. 6: pressure-time curves of NDBP formulations 
Military Technical College

Kobry El-Kobbah,

Cairo, Egypt

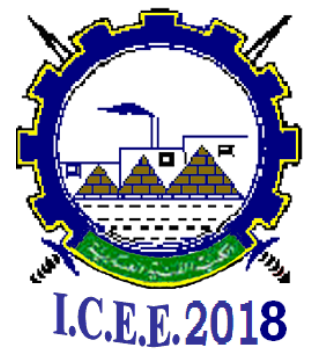

I.C.E.E. 2018 $9^{\text {th }}$ International Conference on

Chemical \& Environmental

Engineering

3-5 April 2018

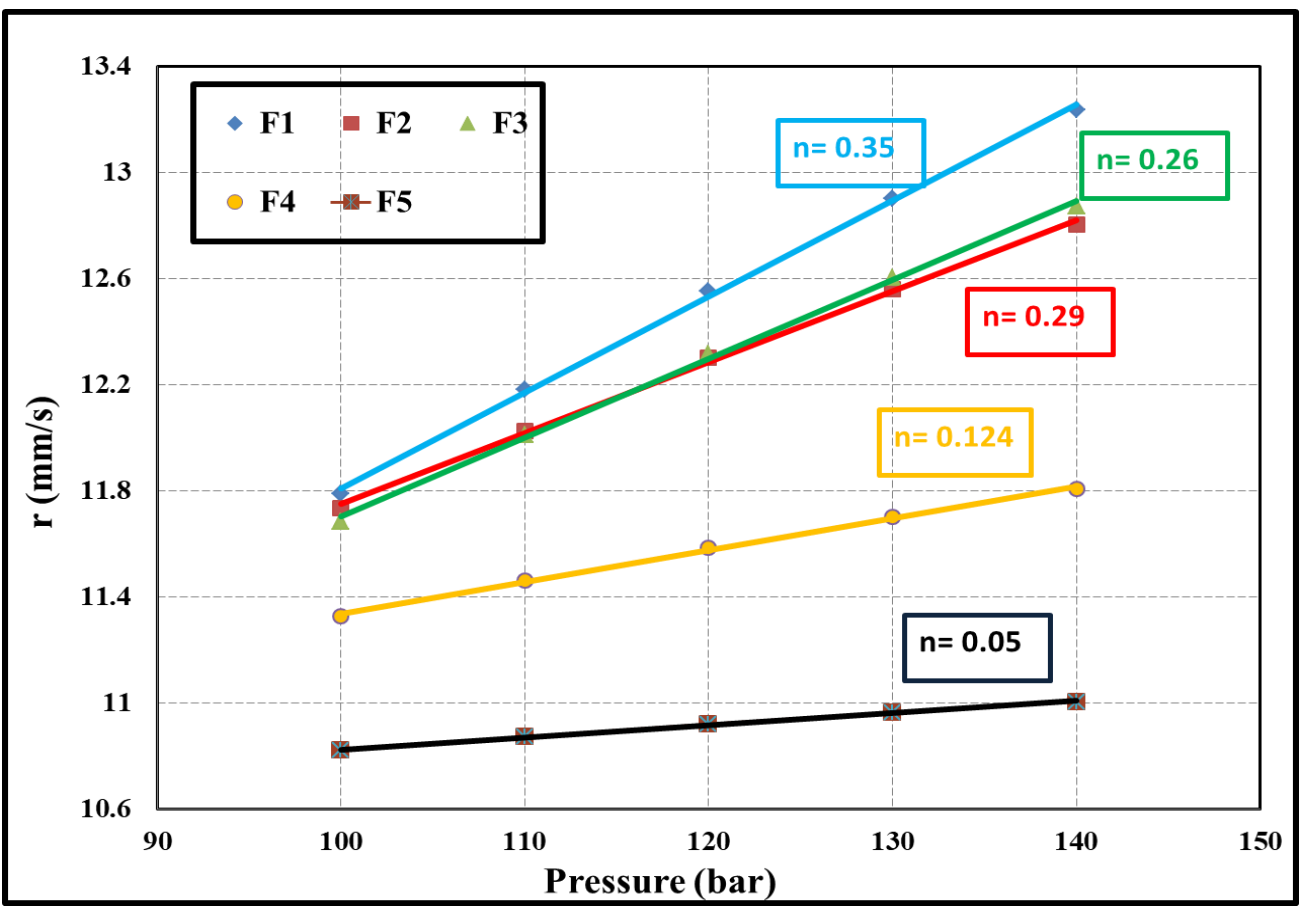

Fig. 7: Burning rate-pressure relation of developed DB propellants

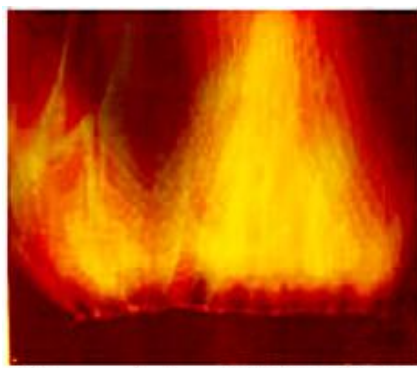

Flame photo of RDX-MDB propellant

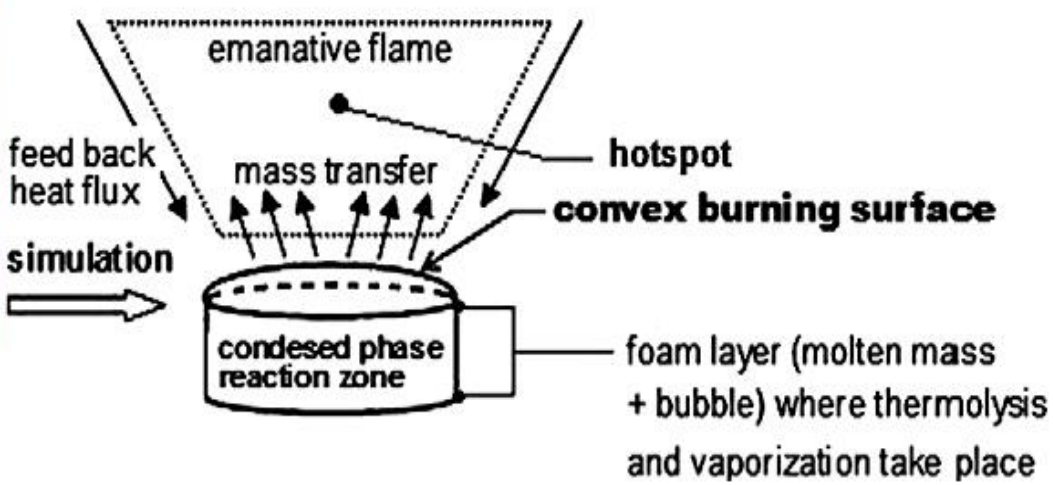

Fig. 8 Typical flame diffusing model for combustion of modified double-base propellants containing nitrogen heterocyclic nitramines 


\begin{tabular}{|l|l|}
\hline Proceeding of the $9^{\text {th }}$ ICEE Conference 3-5 April 2018 & CEA \\
\hline
\end{tabular}

Military Technical College

Kobry El-Kobbah,

Cairo, Egypt

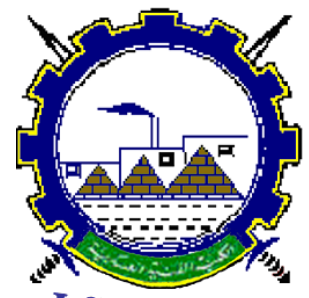

I.C.E.E.2018 $9^{\text {th }}$ International Conference on

Chemical \& Environmental

Engineering

3-5 April 2018

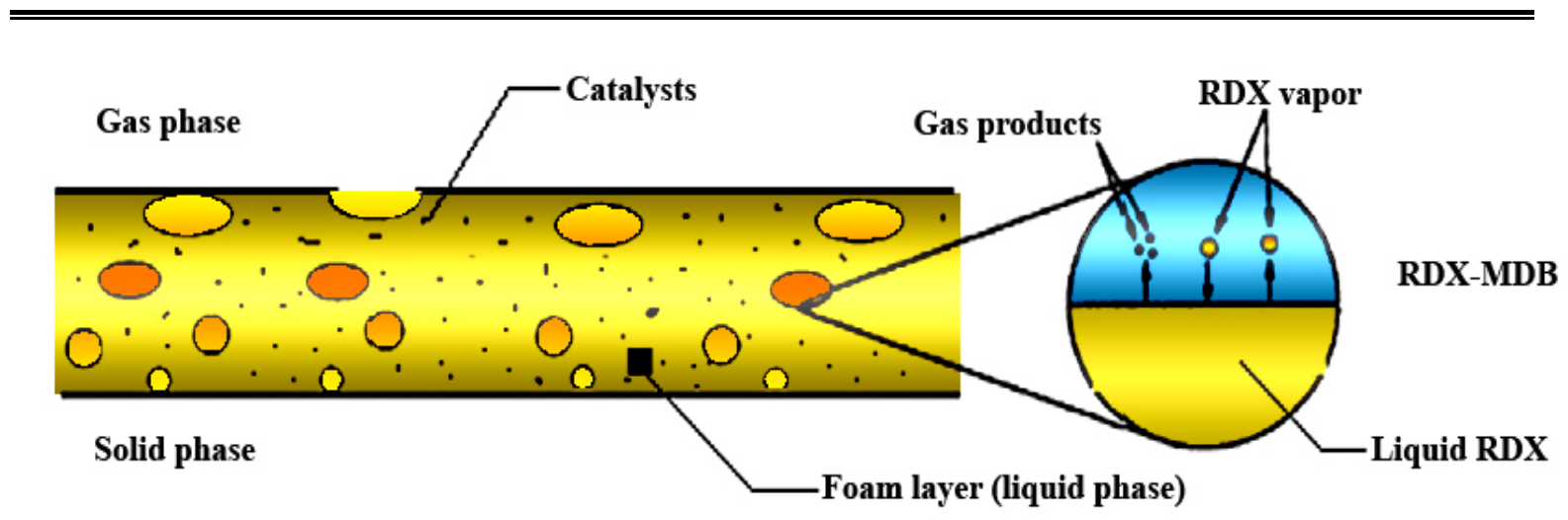

be of excellent fluidness and the liquid will flow to the edge of the burning surface and it make the edge of sample easy to thermolysis

Fig. 9 Schematic diagrams showing various burning surface of typical flame diffusing model for combustion of modified double-base propellants containing nitrogen heterocyclic nitramines 